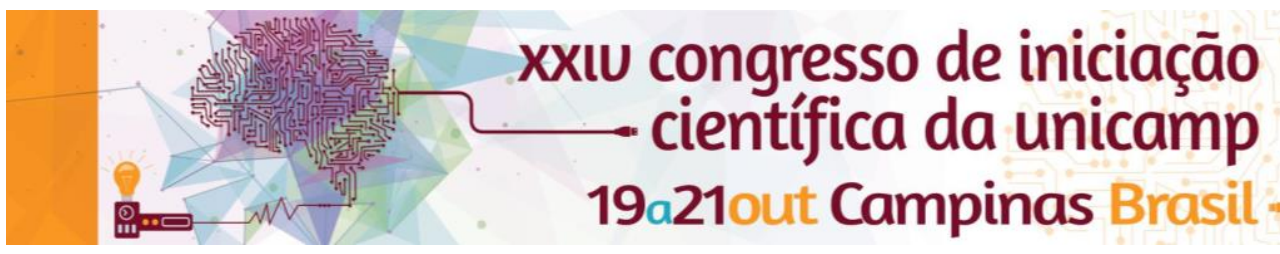

\title{
Fabricação de uma bomba para controle de fluxo duplo de injeção em dispositivos microfluídicos
}

\author{
Filipe Arthur Del Nero*, Varlei Rodrigues, Antonio Riul Junior
}

\section{Resumo}

Este trabalho tem como objetivo principal a construção de uma bomba de seringa que permite o controle independente e simultâneo de dois líquidos distintos no interior de microcanais em geometrias simples. Este trabalho teve como foco a construção da estrutura para montagem da bomba de seringa através de uma impressora 3D e o desenvolvimento de uma interface amigável ao usuário na plataforma Arduino para o controle de um único fluxo.

\section{Palavras-chave:}

microbomba, microfluidica, automação

\section{Introdução}

Microfluídica é a ciência que estuda o comportamento de pequenas quantidades de líquidos pela ação da gravidade, pressão e capilaridade no interior de microcanais, mantendo fluxo laminar. ${ }^{1,2} \mathrm{O}$ controle de fluxo nessas dimensões potencializa o desenvolvimento de sensores e biossensores micro/nanofluídicos, com a vantagem de utilizar microlitros para análise e descarte de amostras, além de aumentar a velocidade de reações. ${ }^{3}$

Neste contexto, o principal objetivo deste projeto é realizar a montagem mecânica e eletrônica para o desenvolvimento de uma bomba para controle individual de dois fluxos independentes em um canal microfluídico, a fim de, no futuro, integrar dispositivos que permitam o desenvolvimento de um dispositivo "lab-on-a-chip". ${ }^{1}$

\section{Resultados e Discussão}

As peças que compõem a estrutura da microbomba de seringa foram projetadas no software OpenScad na forma de script e produzidas em ABS através de uma impressora 3D empregando o software Slic3r. O preenchimento retilíneo de $30 \%$ garantiu o compromisso entre a rigidez mecânica e a confecção de detalhes pequenos nas peças. A Figura 1 ilustra a montagem empregando as peças impressas.

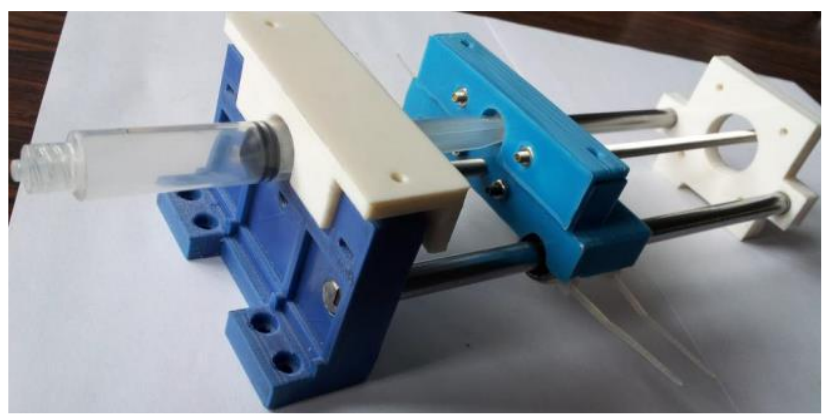

Figura 1. Representação da montagem da microbomba de seringa utilizando OpenScad.
A montagem eletrônica consistiu em um microcontrolador Ardunio UNO, um motor de passo da Kalatec e um driver A4988 para controle do motor. A Figura 2 esquematiza a eletrônica empregada no sistema.

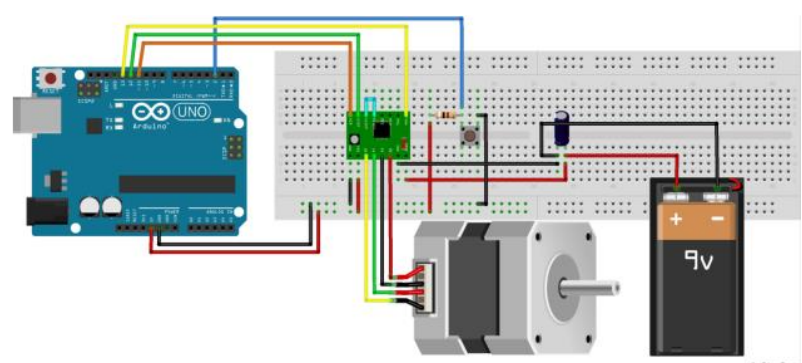

Figura 2. Representação esquemática da eletrônica utilizada na microbomba de seringa através do software fritzing.

A programação do sistema foi realizada através da interface IDE do Arduino, ou seja, um código que permitiu acionar o motor, movimentá-lo no sentido desejado controlando sua velocidade e interromper o movimento quando fosse necessário.

\section{Conclusões}

A construção do código em geral foi bem-sucedida, permitindo o controle do motor de passo de maneira amigável ao usuário. Além disso, as peças projetadas e confeccionadas em uma impressora 3D permitiram desenvolver uma estrutura estável para montagem da bomba de seringa. Portanto, é possível iniciar os estudos dos canais microfluídicos em uma etapa futura.

\section{Agradecimentos}

Agradeço ao PIBIC/CNPq pela concessão da bolsa.

\footnotetext{
$\overline{1}$ Whitesides, G. M. Nature, 2006, 442, 368. (2006)

2 Jokerst, J. C.; Emory, J. M.; Henry, C .S. The Analyst, 2012, 137, 24

3 de Mello, A .J. Nature, 2006, 442, 394
} 